\title{
Uberização das relações de trabalho: uma abordagem transnacional a partir da interrelação entre Direito Público e Privado
}

Crowdsourcing and labor relations: a transnational approach based on the interrelation between Public and Private Law

\section{Raianne Liberal Coutinho}

Universidade de Brasília - Brasília, Distrito Federal, Brasil

\begin{abstract}
Resumo: As plataformas digitais trazem impactos para o trabalho humano, em um fenômeno conhecido como crowdsourcing - ou uberização, como se tornou mais popular no Brasil. Nesse fenômeno, os trabalhadores são considerados pelas plataformas empresários autônomos. Não são, portanto, protegidos por nenhum direito trabalhista, uma vez que se tem dificuldades em se encaixar os tradicionais pressupostos da relação de emprego, juridicamente protegida, nessa forma de trabalho, principalmente no que tange à subordinação. No âmbito do Direito Comparado, no entanto, alguns países caminham para reconhecer a proteção ao trabalhador, como no caso do Reino Unido, por exemplo. Sendo o trabalho por meio das plataformas digitais um modelo de negócio crescente, sendo realizado por empresas multinacionais, é necessário pensar em formas globais de proteção ao trabalhador. Por meio da privatização da lei, atores transnacionais, como os sindicatos globais, podem ser importantes para se garantir a dignidade humana dos trabalhadores, por meio da realização de Acordo Marco Globais, por exemplo. É necessário que um projeto de futuro seja centrado no ser humano, o que somente pode ocorrer por meio de um sistema que valorize os direitos humanos, em especial dos trabalhadores.
\end{abstract}

Palavras-chave: uberização; plataformas digitais; trabalho; sindicatos globais.

\begin{abstract}
Digital Platforms cause a big impact on human labor, a phenomenon known as crowdsourcing or "Uberização", popularly known by the Brazilians. The phenomenon of crowdsourcing has the worker as a freelancer entrepreneur, and for that neglected by all labor laws because of its difficulty of placement in the traditional employment relationship, especially regarding the subordination in the employment relationship. On the scope of Comparative law, however, some nations are moving towards the protection of the
\end{abstract}


crowdsourcing workers, as in the United Kingdom's case, for example. The provision of services through digital platforms is a growing business model and it is being carried out by multinational companies, therefore it is necessary to think about a universal form of worker protection. Through the privatization of the law, transnational actors, such as global unions, can be important in guaranteeing the dignity of the workers through the Global Framework Agreement's achievement, for example. A future project needs to be human-centered and can only happen throughout a system that values Human Rights, especially workers' rights.

Keywords: Crowdsourcing; Uberização; Digital Platforms; Labor relations; Global unions.

Sumário: 1. Introdução. 2. A Quarta Revolução Industrial e a necessidade de proteção ao trabalhador. 3. A uberização das relações de trabalho. 3.1. Uberização e a necessidade de um novo olhar sobre a subordinação. 3.2. Focando no arquétipo: a empresa Uber. 4. A necessidade de um olhar global para a uberização. 4.1. No âmbito público: a decisão do Reino Unido. 4.2. No âmbito privado: os sindicatos globais. 5. Conclusões preliminares

\section{Introdução}

As inovações tecnológicas trazidas pela Quarta Revolução Industrial trazem profundos impactos no mundo do trabalho. Um deles é o trabalho por meio de plataformas digitais, um modelo de negócio crescente em que os trabalhadores são considerados microempresários pelas plataformas, não tendo ela qualquer responsabilidade em termos trabalhistas. Desafiase, portanto, a subordinação jurídica como tradicionalmente é conhecida, herdada da lógica fordista, de trabalho em fábricas.

Esta pesquisa pretende, portanto, discutir a uberização das relações de trabalho, principalmente do ponto de vista da subordinação, um dos pressupostos fático-jurídicos da relação de emprego. Objetiva, ainda, apresentar alguns elementos internacionais e transnacionais sobre o tema, de modo a se mostrar a convergência entre Direito Internacional Público e Privado. Dessa forma, entende-se que, se as empresas são, cada vez mais, multinacionais, a proteção ao trabalhador também deve ultrapassar os limites territoriais. Conclui-se, assim, que é necessário repensar a proteção clássica oferecida ao trabalhador, para que as revoluções tecnológicas sejam focadas no ser humano, não ampliando desigualdades. Ademais, essa proteção deve ser pensada de modo a se criar uma governança global sobre o tema, conforme recomendado pela Organização Internacional do Trabalho (OIT). 
Para elaborar esta pesquisa, foram utilizados métodos qualitativos para abordar as diversas doutrinas sobre o assunto, de modo a se investigar conceitos-chave, como crowdsourcing, uberização e prestação de serviços por meio de plataformas digitais, bem como de sindicatos globais e Acordos Marco Globais. Ademais, seguindo a recomendação das professoras Marci Hoffman e Mary Rumsey (2012, p. 133-135), foi consultado o guia disponível no portal Lexology, que compara as legislações ao redor do mundo, para se compreender como é a relação de trabalho no Reino Unido, para fins de Direito Comparado.

Este artigo está dividido em três tópicos principais. No primeiro deles, são discutidos alguns impactos que a Quarta Revolução Industrial produz no mundo do trabalho, com ênfase nos conceitos de economia sob demanda e na prestação de serviços por meio das plataformas digitais. No segundo, é explorado mais profundamente o conceito de uberização, crowdsourcing e a subordinação no mundo por aplicativos. No terceiro, são trazidas algumas sugestões para o sistema de governança global de proteção ao trabalhador das plataformas digitais, sugerido pela OIT.

\section{A Quarta Revolução Industrial e a necessidade de proteção ao trabalhador}

Atualmente, a sociedade passa por uma transformação que, em razão da sua velocidade, amplitude, profundidade e impacto sistêmico, tem sido classificada como a Quarta Revolução Industrial, sendo distinta de todas as outras. As novas tecnologias têm evoluído em um ritmo exponencial, impactando países, empresas e as próprias pessoas, levando a mudanças estruturais inéditas. Essas mudanças, que irão aproximar os mundos físicos, digital e biológico, terão impacto sobre modelos de negócio, governos e sociedade (SCHWAB, 2016, p. 12-13)

A Quarta Revolução Industrial e as novas tecnologias terão um profundo impacto sobre o mercado de trabalho, eliminando alguns empregos em face da automação, bem como criando profissões decorrentes dessas novas demandas. O problema é que nem sempre a criação de postos de trabalho conseguirá acompanhar a eliminação, de modo que os governos e as instituições precisarão atuar no incentivo à formação acadêmica, evitando conflitos entre o ser humano e esse mundo digital. (SCHWAB, 2016, p. 42.46) 
Caso não sejam adotadas medidas para a proteção do mercado de trabalho, as desigualdades do mercado de trabalho ficarão ainda mais acentuadas. Como destaca Klaus Schwab, a sociedade poderá ser segregada entre as pessoas com altas competências e altos salários, capazes de programar as máquinas, e aquelas de baixa competência e baixos salários, que realizam atividades mecânicas que uma máquina não consegue fazer. (SCHWAB, 2016, p. 51)

Movidos pelo crescimento das tecnologias, têm-se proliferado as plataformas digitais que operam por um modelo de negócio conhecido como economia sob demanda (on-demand economy). Em contraste com a ideia de um trabalhador que labora de forma contínua para uma única empresa, surgem as plataformas que disponibilizam um conjunto de prestadores de serviço, teoricamente autônomos, que estão à espera de uma demanda, de um chamado do consumidor (SIGNES, 2017, p. 29-30) Esse modelo de negócio tem fomentado a crowdsourcing (ou uberização, como é mais conhecida no Brasil), que será abordado mais detalhadamente no próximo tópico.

Por ora, deve-se ter em mente que as plataformas digitais defendem sua atuação argumentando conferirem maior flexibilidade e liberdade ao prestador de serviços. Contudo, o que se observa é que as plataformas estão lucrando em cima de uma legislação menos protetora para os autônomos, remunerando bem os engenheiros de produção e marqueteiros, mas não àqueles que exercem a função principal da empresa. (SIGNES, 2017, p. 2930; SLEE, 2017, p. 23-24) É o que reconhece Klaus Schwab, ao mencionar que a economia sob demanda favorece o desenvolvimento de empresas e startups por esquivá-las pagar salários-mínimos, tributos e benefícios sociais aos supostos autônomos. (SCHWAB, 2016, p. 54)

É necessário, portanto, que o Direito do Trabalho intervenha para proteger o trabalhador da exploração em uma relação assimétrica, garantindo condições favoráveis em novos empregos. (SILVA \& CECATO, 2017, p. 268) Cabe destacar que uma das funções do Direito do Trabalho é garantir a concorrência mantendo patamares mínimos de dignidade humana. Isso significa regular situações de modo a evitar a exploração do trabalho irrestrita diante das mudanças ocorridas a partir da Revolução Industrial - qualquer que seja ela. (OITAVEN, CARELLI \& CASAGRANDE, 2018, p. 40) 
Dessa feita, apesar de as normas que regulam as relações de trabalho serem tradicionalmente classificadas como de Direito Privado, elas não escapam da proteção pública do Estado, uma vez que o direito a um trabalho digno constitui um direito humano reconhecido pela Organização das Nações Unidas, na Declaração Universal de Direitos Humanos de 1948. Na Declaração, está previsto que todo ser humano tem direito a condições justas e favoráveis de um trabalho sem discriminação, com limitação de jornada e um salário que lhe permita uma vida com dignidade. (ONU, 1948, website)

Acerca das transformações sociais ocorridas em decorrência da Quarta Revolução Industrial, a Organização Internacional do Trabalho, por meio da Comissão Global sobre o Futuro do Trabalho, elaborou o relatório "Trabalho para um futuro mais brilhante". Neste, a Comissão salientou que é necessário pensar em uma agenda centrada no ser humano, para que as pessoas sejam as maiores beneficiárias das inovações tecnológicas - e não acabem sendo exploradas por elas. (COMISSÃO GLOBAL SOBRE O FUTURO DO TRABALHO, 2019, p. 11)

Seguindo essa mesma ideia, Klaus Schwab afirma que é necessário pensar a Quarta Revolução Industrial para que ela seja empoderadora e centrada no ser humano. Isso porque "a tecnologia não é uma força externa, sobre a qual não temos nenhum controle. Não estamos limitados entre uma escolha binária entre 'aceitar e viver com ela' ou 'rejeitar e viver sem ela" (SCHWAB, 2016, p. 13-14). Por essa razão, é necessário pensar em estruturas globais de proteção à pessoa e valorização da dignidade humana.

Sendo assim, não se espera impedir a Quarta Revolução Industrial ou o desenvolvimento de novas tecnologias. O que se busca é reafirmar os compromissos estabelecidos pelos países à proteção dos direitos humanos, de modo que as pessoas tenham o direito a um trabalho digno. É o que os próximos capítulos deste artigo procurarão discutir.

\section{A uberização das relações de trabalho}

Como apontado acima, a Quarta Revolução Industrial traz profundos impactos na forma em que se concebe a prestação de trabalho humano. A economia sob demanda também. Os desafios são inúmeros e abrangem 
diversas áreas do Direito. No âmbito trabalhista, um dos aspectos da precarização é por meio da chamada uberização.

\subsection{Uberização e a necessidade de um novo olhar sobre a subordinação}

Dentro da economia sob demanda, as plataformas digitais têm realizado um fenômeno conhecido como crowdsourcing - ou uberização, como o termo ficou mais conhecido no Brasil, em razão da atuação da empresa Uber. No crowdsourcing, uma plataforma digital realiza a gestão de uma atividade econômica, por meio da intermediação entre um trabalhador, e um consumidor, retendo uma parte do pagamento pela realização da atividade. (SIGNES, 2017, p. 31)

O crowdsourcing pode-se realizar de modo genérico (em que a plataforma une prestadores de serviços de diversas atividades - como a Amazon Mechanical Turk) ou específico (em que a plataforma se destina à prestação de uma atividade específica - como o Uber). A atividade prestada pode ser realizada de forma totalmente virtual ou exigir que o trabalhador se desloque fisicamente até determinado local. (SIGNES, 2017, p. 31-32.35)

Este artigo irá se concentrar no crowdsourcing específico e físico, por corresponder ao modelo praticado pela empresa Uber, arquétipo da uberização. Ademais, a subordinação está mais evidente desse modelo. Contudo, reconhece-se a exploração existente no crowdsourcing genérico e virtual, que deve ser discutida e estudada em outras pesquisas.

Para as empresas-aplicativo, no contexto da prestação de serviços por meio de plataformas digitais, os trabalhadores são vistos como "parceiros", "colaboradores" ou "empresários autônomos". Evita-se, assim, utilizar a alcunha de "empregados", afastando-se a proteção jurídica, no caso do Brasil, garantida pela Constituição Federal e pela CLT. (OITAVEN, CARELLI \& CASAGRANDE, 2018, p. 26) Nota-se que a flexibilização, por meio da economia digital, alcançou uma outra forma de perfurar os direitos dos trabalhadores, de modo que essas empresas possam aumentar o seu lucro. (ABÍLIO, 2017, website)

Os pressupostos fático-jurídicos para a configuração de uma relação de emprego tradicional estão dispostos no art. $3^{\underline{0}}$ da CLT: pessoa física, pessoalidade, onerosidade, não-eventualidade e subordinação. Em maior ou menor grau, todos esses pressupostos tentam ser desafiados pelas 
empresas-aplicativos na organização do seu modelo de negócio. Esse é um dos motivos por que se diz que o trabalho por meio das plataformas digitais constitui um desafio ao futuro do trabalho. Contudo, talvez o pressuposto que gere mais debate entre os juristas e pesquisadores seja a subordinação.

A importância que recai sobre a subordinação reside justamente no fato de a sua existência ser a principal diferença entre uma relação de emprego e outras formas de prestação de trabalho, como a contratação de trabalhador autônomo, por exemplo. Apesar de o art. 3o da CLT mencionar a dependência, tradicionalmente tem se entendido que a subordinação do trabalhador é jurídica e objetiva: ela se manifesta por meio do poder de direção que o empregador tem, ao determinar que determinada atividade seja prestada de maneira específica. (DELGADO, 2017, p. 324)

No início do século XX, a subordinação apresentava-se em sua matriz clássica, à luz do modelo fordista, em que os trabalhadores eram reunidos sob a mesma estrutura, tanto física quanto hierárquica, de comando e controle. Essa escala rígida, quase militar, era sustentada por meio de ordens dadas diretamente, em que o trabalhador alienava sua força de trabalho, atuando quase como um ser não pensante. No modelo toyotista, mais comum a partir dos anos 1970, a ideia de hierarquia é atenuada, mas é na atual economia digital que essa lógica sofre uma profunda revolução. (OITAVEN, CARELLI \& CASAGRANDE, 2018, p. 27-30)

No trabalho por meio das plataformas digitais, os trabalhadores parecem gozar de maior autonomia, podendo escolher quando e por quanto tempo trabalhar. Na verdade, essa aparentemente liberdade parece ser justamente a vantagem que atrai as pessoas para essas plataformas. (SCHWAB, 2016, p. 54) Contudo, a subordinação presente nesse aplicativos se molda de uma maneira diferente do que era anteriormente praticado.

Na realidade digital na qual a uberização se insere, o trabalhador é programado para que cumpra metas que são medidas por meio de indicadores estatísticos. Ele tem certa autonomia na prestação da sua atividade, mas deve reagir a comandos. Enquanto em modelos anteriores de produção, o contrato de trabalho estipulava uma quantidade de horas - e se remunerava por elas -, a lógica digital se concentra na própria pessoa 
do trabalhador, que não tem um horário de trabalho definido. (OITAVEN, CARELLI \& CASAGRANDE, 2018, p. 33-35)

Esse trabalhador, portanto, sai da estrutura de hierarquia rígida a que estava submetido e passa a ser subordinado a um aplicativo. Talvez seja esta, então, a contradição desse novo modelo: ao mesmo tempo que o trabalhador tem maior autonomia, ele é menos necessário, porque a necessidade de humanos está sendo paulatinamente substituída por algoritmos. (OITAVEN, CARELLI \& CASAGRANDE, 2018, p. 31-32)

Dessa forma, cria-se uma ideia de mobilização total, em que o trabalhador deve estar disponível a todo momento. Há uma relação de aliança, em que ele não deve apenas obedecer mecanicamente às ordens da empresa, mas se mobilizar totalmente, desde o seu espírito, para cumprimento dos objetivos. Ou seja, há apenas uma ficção de que o trabalhador é livre e autônomo. (OITAVEN, CARELLI \& CASAGRANDE, 2018, p. 35)

Compreender essa nova forma de subordinação é essencial para se entenda a realidade dos trabalhadores submetidos à uberização. Não é porque não há uma hierarquia tão evidente - como ocorria no modelo de produção fordista -, que a subordinação, assim como a relação de emprego, deixou de existir. Ademais, deve ser destacado que, segundo o parágrafo único do art. $6^{\circ}$ da CLT, os meios informatizados de comando e controle se equiparam aos meios pessoais e diretos, para fins de subordinação jurídica.

Exemplos práticos podem ajudar a aclarar melhor essa questão. No próximo tópico, será detalhado como ocorre a subordinação na relação jurídica entre a empresa Uber e seus motoristas. Por ora, o que se percebe é que há a mesma formatação na exploração do trabalho alheio: de um lado, há pessoas, normalmente na forma de pessoas jurídicas, que têm capital para investir em determinada ideia. Do outro lado, há também pessoas, sem capital próprio, que oferecem sua força de trabalho para viabilizar essa ideia. (OITAVEN, CARELLI \& CASAGRANDE, 2018, p. 35) Pode-se estar na Quarta Revolução Industrial, mas a dinâmica entre capital e trabalho parece pouco alterada em relação à dinâmica estabelecida no século XIX.

Ademais, segundo Adrián Signes, a realidade dos prestadores de serviços por meio das plataformas digitais está muito mais perto dos 
trabalhadores do que dos empresários, tendo em vista que a desigualdade de condições entre eles e as plataformas se assemelha à assimetria entre o patrão e o empregado tradicional. (SIGNES, 2017, p. 39) Sendo assim, é necessário repensar as proteções oferecidas ao trabalhador, conforme dito pelo autor:

Por essa razão, pode não ter muito sentido debater se os trabalhadores do século XXI, juridicamente, se encaixam ou não na definição de contrato de trabalho do século XIX, mas sim que a verdadeira questão futura a debater será se a realidade, sobre a qual se discute a proteção oferecida, é a mesma. Com as características vistas em epígrafe se pode constatar uma resposta afirmativa: as necessidades de proteção seguem existindo para os novos trabalhadores, ou como são chamados de "microempresários", sejam dependentes ou independentes. (SIGNES, 2017, p. 39)

Não se pode, portanto, permitir a flexibilização das relações trabalhistas a partir do mascaramento da relação jurídica por meio de termos como "colaboradores" ou "parceiros", sob o risco de se alcançar impactos negativos para a própria economia. Ademais, os benefícios aos consumidores - como, no caso da Uber, na oferta de um serviço de transporte mais barato -, não podem ser utilizados como justificativa para a precarização das relações de trabalho. (OITAVEN, CARELLI \& CASAGRANDE, 2018, p. 26-27) Conforme lembra Klaus Schwab (2016, p. 17.20), somos todos consumidores e produtores. Dessa forma, ainda que as plataformas digitais tragam benefícios aos consumidores, eles não podem ser aceitos se precarizarem as relações de trabalho. Além disso, há o risco de que a precarização do trabalho amplie as desigualdades sociais, criando agitações sociais e instabilidade política.

Para finalizar, costuma-se falar em sobre uberização e associá-la aplicativo de transportes Uber. De fato, hoje a prestação de serviços por meio de plataformas digitais encontra modelo no que é praticado por essa empresa-aplicativo. Outras empresas, contudo, funcionam com lógicas semelhantes, como a Loggi e a iFood. O crowdsourcing também pode estar presente em outros aplicativos com modelos de negócio semelhante, distintos do ramo de transporte, como o Lavô Online, de lavagem de carros, o Manicury, de serviços de manicure e pedicure, e o Amazon Mechanical Turk, para realização de tarefas mecânicas. Se esses aplicativos são apenas plataformas digitais que conectam oferta e demanda ou se, na realidade, mascaram uma relação de emprego, é algo que necessita ser 
analisado caso a caso. É possível perceber, no entanto, que a uberização tem potencial de alcançar diversos ramos de atividade.

\subsection{Focando no arquétipo: a empresa Uber}

Como dito, o modelo de negócios adotado pela Uber é um dos principais exemplos do fenômeno da uberização (como o próprio nome sugere). Com base nisso, a partir de agora, este artigo se debruça sobre a relação jurídica entre essa empresa e seus motoristas.

A Uber Technologies Inc. tem sede em São Francisco, nos Estados Unidos. Apresentam-se como uma empresa de tecnologia, cuja principal atividade é conectar, por meio de um aplicativo, motoristas e usuários previamente cadastrados. Dessa forma, o software - e, por consequência, a empresa - apenas estaria fazendo a intermediação dessas viagens remuneradas. (SILVA \& CECATO, 2017, p. 260)

Segundo dados de agosto de 2020, fornecidos pela própria empresa, a Uber está presente em 69 países e em mais 10 mil cidades ao redor do mundo. Há 103 milhões de usuários ativos em todo mundo, para 5 milhões de motoristas e entregadores, responsáveis por uma média de 18 milhões de viagens e entregas por dia. (UBER NEWSROOM, 2020, website) Esses números mostram a dimensão da empresa, bem como seu alcance global, que será abordado mais para frente.

A classificação da Uber como uma empresa de tecnologia, e não como uma empresa de transporte de passageiros, tem sido útil para criar um gap regulatório que a afasta da classificação com os táxis, o que cria uma concorrência desleal. De fato, o serviço de táxi é regulado por regras específicas que envolvem vistorias, licenciamentos, obrigações e taxas. A Uber, por outro lado, opera em uma estrutura com regras mais flexíveis, que a permitem filtrar quem são os motoristas sem ter que arcar com outras obrigações típica dos taxistas. (SLEE, 2017, p. 105)

Essa distinção entre empresa de tecnologia ou serviço de transporte de passageiros é importante por outras razões. A dinâmica entre a empresa e seus motoristas (chamados, erroneamente, de parceiros) evidenciam uma possível relação de subordinação, o que vem suscitando discussões em diversos países sobre o vínculo de emprego. 
Como de praxe nas empresas que ofertam pela economia sob demanda, os motoristas da Uber são considerados empresários, de modo que, supostamente, atuam de forma autônoma. Um empresário pode, normalmente, fixar o preço do seu serviço, bem como escolher seus clientes. Não é o que ocorre na dinâmica da Uber. Os motoristas têm uma obrigação de aceitar uma porcentagem das corridas, ou poderão sofrer sanções. A média da sua avaliação pelos usuários - que varia de uma a cinco estrelas - também é constantemente monitorada pela plataforma, de modo que ele pode acabar sendo desativado se ela estiver abaixo de determinado valor. (SLEE, 2017, p. 129-131)

O preço também não é fixado pelos motoristas, mas pela plataforma, a partir de um algoritmo que é controlado pela própria empresa. Ainda que os motoristas possam trabalhar a hora que eles quiserem (o que tem sido uma argumentação para afastar a relação empregatícia), há o estímulo para eles trabalharem o maior tempo possível, de modo a sempre haver motoristas disponíveis quando o usuário necessitar. Há também determinações acerca da idade do carro que pode ser utilizado para transporte. (OITAVEN, CARELLI \& CASAGRANDE, 2018, p. 36)

Nota-se que o motorista é constantemente controlado. Sua localização é monitorada mesmo quando ele não está trabalhando, assim a plataforma pode ter informações sobre o seu trajeto diário. Há uma técnica ambivalente de premiações e punições, em que os motoristas são incentivados a irem a lugares de difícil acesso ou trabalhar em dias festivos, para receberem um valor maior pela corrida, ao mesmo tempo que temem uma avaliação negativa dos usuários. (OITAVEN, CARELLI \& CASAGRANDE, 2018, p. 36-37)

Com base nessas informações, parece haver subordinação entre a empresa Uber e seus motoristas, ainda que esta relação ocorra de modo distinto do que era praticado no antigo modelo fabril. Para as pesquisadoras Juliana Silva e Maria Áurea Cecato, a partir disso, é necessário analisar a atividade econômica desenvolvida pela Uber sobre um outro olhar:

A atividade econômica desenvolvida pela plataforma do Uber também deve ser analisada sob o prisma constitucional acima exposto. Com efeito, apesar de possuir uma roupagem, pelo menos da teoria, de "economia compartilhada", o que se percebe é que a plataforma online tem desvirtuado a ideia original, ao intermediar o uso de bens e serviços e promover um verdadeiro mercado de baixo custo, ideia 
que se distancia de um compartilhamento propriamente dito. (SILVA \& CECATO, 2017, p. 268)

Acerca da subordinação, geralmente argumenta-se que os motoristas podem trabalhar a hora que quiserem, não estando, dessa forma, recebendo ordens do aplicativo. Contudo, como mostrado no tópico anterior, o que se entende por um trabalho subordinado vem sendo alterado ao longo dos anos, diante da própria dinamicidade das relações sociais. É preciso, portanto, atualizar a forma como a proteção social é estabelecida, uma vez que as inovações - e as novas formas de exploração do trabalho - estão em constante alteração. O próximo tópico debaterá possíveis caminhos de ação no âmbito internacional.

\section{A necessidade de um olhar global para a uberização}

A globalização e, especialmente, as empresas multinacionais desafiam as concepções atuais de território, um dos elementos para a definição de um Estado. Dessa forma, para as relações transnacionais, os governos estão reagindo dando menos ênfase no território, e mais na aplicação da lei. (MICHAELS, 2013, p. 9-10) O importante, numa sociedade global, é proteger direitos, pensando além de fronteiras.

É essa lógica que deve ser considerada quando se trata do impacto das plataformas digitais na sociedade. Sendo a Uber uma empresa multinacional, os dilemas - e aqui destaca-se o trabalhista - que os governos e os juristas encontram ao lidar com essa nova tecnologia são compartilhados globalmente. Dessa forma, uma análise internacional para o tema é importante para conhecer como outros países abordaram a questão e para pensar estratégias globais para proteção aos motoristas.

Cabe destacar que, no relatório "Trabalho para um futuro mais brilhante", já mencionado, a Comissão Global sobre o Futuro do Trabalho da OIT sinalizou que, no tocante às plataformas digitais, é recomendável a criação de um sistema de governança internacional, de modo a se garantir uma proteção social mínima a todos os trabalhadores do mundo:

As plataformas de trabalho digital fornecem novas fontes de renda para muitos trabalhadores em diferentes partes do mundo, mas a natureza dispersa do trabalho em jurisdições internacionais dificulta o monitoramento da conformidade com as leis trabalhistas aplicáveis. O trabalho às vezes é mal remunerado, muitas vezes abaixo do salário mínimo vigente e não existem 
mecanismos oficiais para lidar com o tratamento injusto. Como esperamos que essa forma de trabalho se expanda no futuro, recomendamos o desenvolvimento de um sistema de governança internacional para plataformas de trabalho digital que definam e exijam que as plataformas (e seus clientes) respeitem certos direitos e proteções mínimas. (COMISSÃO GLOBAL SOBRE O FUTURO DO TRABALHO, 2019, p. 44)

Como já falado, o Direito do Trabalho surge para permitir que a concorrência ocorra garantindo a dignidade humana. No âmbito internacional, principalmente na figura da OIT, a proteção surge "para que um país não realize competição desleal em face de outro, impedindo a imposição de padrões não razoáveis de vida e trabalho." (OITAVEN, CARELLI \& CASAGRANDE, 2018, p. 40)

Por exemplo, conforme já falado, o crowdsourcing pode ocorrer de forma totalmente virtual, de modo que trabalhadores de todo mundo competiram, e aqueles de países com legislações menos protetivas levariam vantagens. Por essa razão, é necessária uma atuação global para se lidar com o avanço das plataformas digitais.

O sistema de governança global mencionado pela Comissão precisa da colaboração de diversos atores para que seja efetivo. Nos próximos tópicos, serão apresentados dois caminhos possíveis para o tratamento internacional sobre o tema. O primeiro traz uma perspectiva doméstica e no âmbito público - afinal, uma governança global que aborde o trabalho por meio das plataformas digitais necessita da sensibilização de países, individualmente, sobre o tema. O segundo tópico traz um possível enfrentamento a nível transnacional, no âmbito privado.

\subsection{No âmbito público: a decisão do Reino Unido}

Em 2018, a Court of Appeal de Londres manteve a decisão do Employment Tribunal e Employment Appeal Tribunal que classificaram como workers os motoristas da empresa Uber, em uma ação movida por dois exmotoristas. Os tribunais descartaram a ideia de que os motoristas seriam empresários autônomos, uma vez que eles não estariam livres para determinar a tarifa que cobrariam ou recusar viagens. Ademais, foi reconhecido que a Uber mantinha um controle constante sobre os motoristas, instruindo-os a realizar o seu trabalho. (FRAZÃO, 2017, p. 318319) 
O status jurídico de workers (trabalhadores) é diferente de ser employee (empregado) ou self-employed (autônomo). Foi um avanço jurisprudencial afastar a argumentação da empresa Uber de que os trabalhadores seriam empresários autônomos, não lhe sendo devidos nenhum direito trabalhista, portanto. Contudo, o tribunal não os considerou como empregados plenos, e é essa diferença é importante quando se jurisprudência em Direito Comparado.

O termo workers já é uma flexibilização em relação ao employee, status jurídico mais bem protegido, e vem sendo aplicado às empresas da chamada Gig Economy. Os workers têm, no entanto, alguns direitos básicos assegurados, como salário-mínimo e descanso semanal remunerado. (NOBLET, 2018, website) Nota-se que, mesmo em uma relação flexível, os direitos humanos do trabalhador, previstos na Declaração Universal de Direitos Humanos, estão protegidos. Ou seja, o sistema jurídico do Reino Unido entende que há um mínimo que deve ser garantido. Situação que não ocorre no Brasil, em que o mero status de trabalhador não lhe assegura qualquer direito.

Há outra lição que pode ser retirada da decisão do tribunal inglês, no tocante ao Princípio da Primazia da Realidade sobre a Forma, muito caro à proteção do trabalhador, tanto nacional como internacionalmente. $\mathrm{O}$ contrato entre o motorista e a Uber é expresso ao ressaltar que há uma relação de parceria, não de emprego. Contudo, os juízes foram além das disposições contratuais, para considerar a realidade que estava sendo mascarada por meio do que tinha sido escrito pelo "exército de advogados". Com isso, o Tribunal mostrou sensibilidade ao entender quem, de fato, exerce o poder empresarial - a empresa Uber, não os motoristas. (FRAZÃO, 2017, p. 320)

Ademais, cabe destacar que, enquanto uma sociedade baseada no sistema da common law, uma decisão judicial que reconheça o vínculo trabalhista com a empresa Uber, ainda mais da Court of Appeal, gera um precedente importante para decisões futuras. Enquanto fonte imediata do Direito, as decisões judiciais podem dar uma resposta mais rápida e efetiva do que as legislações positivas. Isso porque os tribunais estariam mais sensíveis a aplicar o Princípio da Primazia da Realidade sobre a Forma, por estarem analisando o caso concreto. 
As legislações positivadas, por outro lado, poderiam não ter a mesma interpretação. A lei parte de uma definição apriorística de determina relação, o que não quer dizer essa situação não possa ser alterada em razão de comportamentos supervenientes das partes. É necessário estar atento a essas mutações das relações jurídicas, que não necessariamente estão espelhadas em documentos contratuais. (FRAZÃO, 2017, p. 320)

Também não se quer dizer que a lei não tenha importância. Nota-se que somente foi possível o reconhecimento do status de workers aos motoristas porque havia antes uma legislação que dispunha, ainda que de forma não esgotável, sobre os direitos dos trabalhadores. O que se ressalta é a importância de se ter sensibilidade ao caso concreto, que deve olhar além do que está escrito.

Contudo, as fontes positivadas do Direito também podem contribuir para a proteção social do trabalhador. O próximo tópico analisará uma possibilidade de uma negociação coletiva entre atores privados internacionais que permita ampliar os direitos dos trabalhadores submetidos à uberização.

\subsection{No âmbito privado: os sindicatos globais}

A despeito da importância dada à decisão do Reino Unido, uma solução regionalizada, adotada por um país, pode não ser a mais eficiente para se lidar com empresas multinacionais, como é o caso da Uber. Um dos exemplos mais visíveis da convergência entre Direito Público e Direito Privado são os poderes assimétricos das partes, em que não se sabe qual é o superior: enquanto os Estados têm a sua soberania, as empresas têm seus recursos financeiros. (MICHAELS, 2013, p. 17) Dessa forma, um Estado, no uso do seu poder soberano, poderia impor certas condições ao funcionamento das plataformas digitais, mas a empresa multinacional pode optar por não seguir e deixar de operar naquele território, causando prejuízos econômicos ao país.

Dessa forma, sendo a Uber uma empresa multinacional, uma forma de garantir a proteção dos seus trabalhadores seria por meio de uma abordagem transnacional para o tema. Contudo, se os países ainda estão em processo de amadurecimento para consolidar sua jurisprudência ou marcos legislativos acerca do tema, como é possível que eles se unam criar 
um marco regulatório internacional? Um dos caminhos pode ser, portanto, por meio da privatização da lei.

Segundo Ralf Michaels, ainda no âmbito da convergência entre público e privado, as legislações privadas podem ser uma forma de superar o gap regulatório dos países diante de uma realidade mutável e inovadora. Nesse caso, atores privados podem criar mecanismos unilaterais ou bilaterais com o objetivo de garantir maior proteção social ou ao meio ambiente, por exemplo. Eles teriam a vantagem de cruzar fronteiras, uma vez que as legislações públicas estão limitadas a um território. Também poderiam contar com grupos responsáveis pela fiscalização do cumprimento, como organizações da sociedade civil, por exemplo. (MICHAELS, 2019, p. 168-170)

Tendo como base essa perspectiva teórica, entende-se que os sindicatos globais e os Acordo Marco Internacionais podem promover avanços no que tange à proteção dos trabalhadores que prestam serviço por meio de plataformas digitais, de modo a se combater a uberização e a precarização das relações de trabalho.

Os sindicatos globais são pessoas jurídicas de direito privado, constituídas em determinado Estado e compostas por organizações de trabalhadores de diversos países, de modo a atuar a nível global e local. Visam, portanto, a melhoria das condições de trabalho a nível mundial, por meio do reconhecimento de direitos trabalhistas individuais e coletivos e a promoção de formas de diálogo com as partes envolvidas. (LOPEZ, 2014, p. 80)

Tradicionalmente, diante de uma lógica localizada, os sindicatos tinham atuação limitada à base territorial no qual estavam organizados, podendo ter atuação em nível local, regional ou nacional. Com a globalização, a economia internacional passa a afetar as políticas de salário e proteção social, de modo que os trabalhadores locais são indiretamente afetados por essas flutuações de mercado. Dessa forma, os sindicatos necessitam estar preparados. (LOPEZ, 2014, p. 78)

Ademais, a lógica por trás dos sindicatos globais tem outra origem. A expansão das empresas multinacionais tem desafiado as fronteiras de proteção aos direitos sociais, inclusive os trabalhistas. Entende-se que, se o capital está cada vez mais internacionalizado, as formas de garantia aos direitos sociais também devem estar, para que um Estado não sofra com o 
dumping social em relação a outro, por exemplo. Dessa forma, os sindicatos nacionais têm buscado se associar com outras entidades, de modo a criar uma rede de defesa aos direitos dos trabalhadores. (MOURA \& GONÇALVES, 2017, p. 296)

As federações sindicais internacionais existentes, assim como a lógica desenvolvida em âmbito doméstico, organizam-se por categorias. Há federações representantes dos trabalhadores do setor da Educação (Education International - EI) e para os trabalhadores dos setores de alimentação, turismo, agricultura e tabaco (International Union of Food, Agricultural, Hotel, Restaurant, Catering, Tobacco and Allied Workers' Associations - IUF), por exemplo. (GLOBAL UNIONS, 2019, website)

Ainda não há uma federação sindical internacional específica para os trabalhadores que prestam serviço por meio das plataformas digitais. Há a International Transport Workers' Federation (ITF), federação sindical cujo foco são os trabalhadores dos serviços de transporte. Ela está presente em 147 países, com escritórios, inclusive, no Brasil, no Rio de Janeiro. (INTERNATIONAL TRANSPORT WORKERS' FEDERATION, 2019d, website). Há seis federações sindicais e sindicatos brasileiros afiliados à ITF, abrangendo trabalhadores da aviação civil e ferroviários. (INTERNATIONAL TRANSPORT WORKERS' FEDERATION, 2019a, website)

Destaca-se que ela não é específica para trabalhadores em plataformas digitais. Iniciativas internacionais para defesa desses trabalhadores começam a ser adotadas. Em 2020, foi criada a Transnational Workers Network (TWN) - ou, em português, a Rede Transnacional de Trabalhadores (RTT), uma organização internacional para defender os trabalhadores de plataformas, como motoristas e entregadores. Trata-se de uma iniciativa de trabalhadores, coletivos e sindicatos de diversos países, como Estados Unidos e Canadá. O objetivo é que trabalhadores possam encontrar na Rede uma ferramenta para defender seus direitos contra empresas multinacionais da Economia do Bico. (IHU, 2020, website) É importante a criação de uma organização ou sindicato global específico para os trabalhadores em plataformas digitais, haja vista que as demandas particulares deles poderão ser atendidas mais propriamente.

Um dos mecanismos de atuação desses sindicatos globais não é muito diferente das estratégias utilizadas pelos sindicatos nacionais para o 
aprimoramento da legislação trabalhista: as negociações coletivas. Dessa forma, têm-se os Acordos Marco Globais - ou Acordos Marco Internacionais ou Global Framework Agreement, em inglês.

Cabe destacar que o direito à negociação coletiva constitui um dos direitos fundamentais do trabalho reconhecidos pela OIT na Declaração sobre os Princípios e Direitos Fundamentais no Trabalho, de 1998. (LOPEZ, 2014, p. 79) Ademais, ela é uma forma de autocomposição de conflitos que constitui o cerne do princípio da adequação setorial negociada. No Brasil, a negociação coletiva é materializada por meio do acordo coletivo e a convenção coletiva de trabalho. (GODINHO, 2017, p. 1568)

Os Acordo Marco Globais elevam a negociação coletiva a um nível internacional. São acordos bilaterais entre uma empresa multinacional e uma federação sindical global, de modo a estabelecer normas que garantam, minimamente, direitos dos trabalhadores de determinada empresa em todos os países em que opera, bem como na sua cadeia produtiva. Seus conteúdos são diversos, podendo abranger disposições sobre saúde e segurança do trabalho, compromissos remuneratórios e limitação de jornada. É possível também o estabelecimento de uma cláusula social para garantia do cumprimento de padrões mínimos de proteção também pelas fornecedoras e subsidiárias. (MOURA \& GONÇALVES, 2017, p. 302)

Há alguns desafios no que tange à utilização dos Acordo Marco Globais. Em nível regional, eles ainda são pouco conhecidos enquanto forma de proteção dos direitos dos trabalhadores. Ademais, há dificuldades na sua implementação e fiscalização: ainda que tenham caráter cogente, é necessário que os sindicatos nacionais e as federações sindicais internacionais adotem medidas inovadoras para garantir o seu cumprimento. Ainda assim, são uma fonte importante do Direito do Trabalho, como forma de se ampliar os compromissos internacionais assumidos por determinada empresa, detendo eficácia extraterritorial. (LOPEZ, 2014, p. 93; MOURA \& GONÇALVES, 2017, p. 299)

Até o momento de elaboração desse artigo, não há Acordos Marco Globais firmados pela Uber e qualquer sindicato global ou organização internacional. Contudo, em 2018, a ITF discutiu os impactos que a tecnologia e a automação teriam sobre os trabalhadores de transporte, 
concluindo que os efeitos seriam diferentes para mulheres e os mais jovens. Dessa forma, uma das estratégias adotadas, além do maior envolvimento de mulheres e jovens líderes, é a coordenação e apoio de campanhas que possam promover práticas inovadoras na defesa dos trabalhadores em empresas multinacionais. (INTERNATIONAL TRANSPORT WORKERS' FEDERATION, 2019b, website)

Ademais, a federação sindical mantém-se em contato com os motoristas de Uber. Em maio de 2019, motoristas europeus se reuniram com federações sindicais demandando, por exemplo, salário mínimo e aprimoramento das condições de saúde e segurança dos motoristas. Salientaram que era uma ficção considerar os motoristas como autônomos, mantendo-os pobres, enquanto os donos da empresa aumentavam seus rendimentos. Ademais, foi ressaltado que o modelo de negócios adotado pela Uber é divulgado como algo inovador e bom, mas nada mais é do que uma forma de exploração e péssimas condições de trabalho. Afirmou-se também o papel dos sindicatos, nacionais e globais, na defesa dos direitos dos trabalhadores. (INTERNATIONAL TRANSPORT WORKERS' FEDERATION, 2019c, website)

\section{Conclusões}

Como visto, as plataformas digitais têm potencial para mudar a forma como o trabalho é desempenhado. O crowdsourcing e a uberização atingiriam fortemente a logística de transportes, de carga ou de passageiros, mas são fenômenos que podem impactar diversos ramos de atividades. Ou seja, é possível que, cada vez mais, haja um contingente de trabalhadores prestando serviços em nuvens, realizando pequenas tarefas a um valor irrisório, sem desenvolverem vínculos jurídicos de proteção.

A preocupação recai justamente neste cenário de precarização. Atualmente, o trabalho uberizado não está abarcado por nenhum direito trabalhista, salvo em casos específicos de alguns países, que reconheceram, por exemplo, a relação jurídica de "trabalhador" ao motorista de Uber, como o Reino Unido, citado neste artigo. Para a maioria dos casos, no entanto, os trabalhadores, motoristas ou não, são classificados como microempresários, arcando com o custo da atividade. Dessa forma, a plataforma digital não tem qualquer responsabilidade social e recebe ainda uma contrapartida pelo trabalho do prestador de serviço. 
É necessário garantir a dignidade humana para os trabalhadores da uberização, sob o risco de, sendo este um modelo de negócio crescente, terse cada vez mais um contingente de pessoas desabrigadas pelo sistema de proteção trabalhista. Esse cenário agravaria a desigualdade social, gerando instabilidade política, por exemplo, porque essas pessoas ganhariam uma remuneração irrisória, suficiente apenas para garantir seu sustento básico, tendo pouca perspectiva de melhoria para o futuro.

Um caminho pode ser a estratégia adotada pelo Reino Unido, ampliando a proteção trabalhista a todos os trabalhadores, não somente àqueles considerados empregados. Sendo assim, um caminho poderia ser repensar os clássicos pressupostos jurídicos da relação de emprego, adotando uma classificação que esteja em conformidade com as mudanças ocorridas no mundo do trabalho neste século.

Deve-se ter em mente que as relações humanas são dinâmicas, de modo que o Direito também deve ser, caso contrário, poderá se ter grave violação aos direitos humanos. As alterações no Direito do Trabalho, contudo, devem sempre visar a ampliação do seu padrão protetivo, pois só assim alinha-se com o que está disposto na Constituição Federal e com o que é estabelecido por organismos internacionais, como a ONU e a OIT.

Ademais, considerando que as plataformas digitais podem não estar limitadas pelo território de um país, é necessário também pensar em um sistema de proteção transnacional, conforme mencionado pela OIT. Diante de uma ausência de vontade política - ou até mesmo de um amadurecimento jurídico - dos países para se fazer uma convenção internacional, uma possível abordagem para o caso pode ser por atores e mecanismos privados, como foi citado o exemplo dos sindicatos globais e os Acordo Marco Globais.

Em qualquer caso, é importante ter em mente que as empresas também têm o dever de garantir os direitos humanos, sendo necessário que se desenvolva a sua responsabilidade social corporativa. Isso não é ser contra o processo ou as revoluções industriais; é, na verdade, ser capaz de pensar no desenvolvimento social como o objetivo primeiro de qualquer inovação tecnológica, de modo que se tenha uma abordagem centrada e empoderadora do ser humano. 


\section{Referências bibliográficas}

ABÍLIO, Ludmila Costhek. Uberização do trabalho: subsunção real da viração. Texto publicado em 22 de fevereiro de 2017. Disponível em < https://blogdaboitempo.com.br/2017/02/22/uberizacao-do-trabalho-subsuncaoreal-da-viracao/> . Acesso em 9 de julho de 2019.

BRASIL. Decreto-Lei no 5.452, de 1ํㅡㄹ de maio de 1943. Aprova a Consolidação das Leis do Trabalho. Publicado em 9 de agosto de 1943.

COMISSÃO GLOBAL SOBRE O FUTURO DO TRABALHO. Trabalho Para Um Futuro Mais Brilhante. Escritório Internacional do Trabalho. Genebra: OIT, 2019.

DELGADO, Mauricio Godinho. Curso de Direito do Trabalho. 16 ed ed. São Paulo: LTr, 2017.

FRAZÃO, Ana. A decisão do Reino Unido sobre os motoristas da Uber: o que temos a aprender com ela? In: LEME, Ana Carolina Reis Paes; RODRIGUES, Bruno Alves; CHAVES JÚNIOR, José Eduardo de Resende. Tecnologias disruptivas e a exploração do trabalho humano. São Paulo: LTr, 2017. P. 318-322 GLOBAL UNIONS. Disponível em: http://www.global-unions.org/?lang=en. Acesso em 30 de outubro de 2020.

HOFFMAN, Marci; RUMSEY, Mary. International and foreign legal research: a coursebook. Martinus Nijhoff, 2012. $2^{\mathrm{a}}$ ed.

IHU. Nasce um sindicato global contra a economia de plataforma. Publicado em 29 de junho de 2020. Disponível em: http://www.ihu.unisinos.br/78noticias/600400-nasce-um-sindicato-global-contra-a-economia-de-plataforma.

Acesso em 30 de outubro de 2020.

INTERNATIONAL TRANSPORT WORKERS' FEDERATION. ITF Affiliiates. Disponível em: https://www.itfglobal.org/en/aboutus/affiliates?title $=\&$ field_country_target_id $=120$. Acesso em 30 de outubro de 2020.

. ITF strategy. Disponível em: https://www.itfglobal.org/en/aboutus/strategy. Acesso em 30 de outubro de 2020.

. Uber drivers speak out about treatment. Publicado em 9 de maio de 2019. Disponível em: https://www.itfglobal.org/en/news/uber-drivers-speak-outabout-treatment. Acesso em 30 de outubro de 2020.

. Who we are. Disponível em: https://www.itfglobal.org/en/aboutus/who-we-are. Acesso em 30 de outubro de 2020. 
LOPES, Inez. Sindicatos Globais e a Proteção dos Direitos Trabalhistas. In: DELGADO, Gabriela Neves; PEREIRA, Ricardo José Macêdo de Brito (coord) Trabalho, Constituição e Cidadania: a dimensão coletiva dos direitos sociais trabalhistas. São Paulo, LTr Editora: 2014. P. 78-96.

MICHAELS, Ralf. Globalization and Law: Law Beyond the State. In: Law and Social Theory. Oxford: Hart Publishing, 2013. 2ª edição. P. 287-303.

. The Dual Privatization of Law in Globalization (Note on Kasky v Nike). In: WATT, Horatia Muir et all eds. Global Private Internacional Law: Adjudication without Frontiers. Edgal: 2019. P. 162-171.

MOURA, Natália das Chagas; GONÇALVES, Márcio Toledo. Atuação sindical transnacional: as redes sindicais internacionais e os acordos marco globais. In: LEME, Ana Carolina Reis Paes; RODRIGUES, Bruno Alves; CHAVES JÚNIOR, José Eduardo de Resende. Tecnologias disruptivas e a exploração do trabalho humano. São Paulo: LTr, 2017. P. 296-303.

NOBLET, Caroline. Employment \& labour law in the United Kingdom. Lexology: 13 de novembro de 2018. Disponível em $<$ https://www.lexology.com/library/detail.aspx?g=ccd13a56-2017-40e2-b5e6$66 \mathrm{a} 041 \mathrm{db} 20 \mathrm{e} 8>$ Acesso em 27 de julho de 2019.

OITAVEN, Juliana Carreiro Corbal; CARELLI, Rodrigo de Lacerda; CASAGRANDE, Cássio Luís. Empresas de transporte, plataformas digitais e a relação de emprego: um estudo do trabalho subordinado sob aplicativos. Brasília: Ministério Público do Trabalho, 2018.

ONU, Declaração Universal dos Direitos Humanos, 1948. Adotada e proclamada pela Assembleia Geral das Nações Unidas (resolução 217 A III) em 10 de dezembro $1948 . \quad$ Disponível em: https://www.ohchr.org/EN/UDHR/Pages/Language.aspx?LangID=por. Acesso em 30 de outubro de 2020.

SCHWAB, Klaus. A Quarta Revolução Industrial. São Paulo: Edipro, 2016.

SIGNES, Adrián Todolí. O Mercado de Trabalho no Século XXI: ondemandeconomy, crowdsourcing e outras formas de descentralização produtiva que atomizam o mercado de trabalho. In: LEME, Ana Carolina Reis Paes; RODRIGUES, Bruno Alves; CHAVES JÚNIOR, José Eduardo de Resende. Tecnologias disruptivas e a exploração do trabalho humano. São Paulo: LTr, 2017. P. 28-43.

SILVA, Juliana Coelho Tavares da; CECATO, Maria Áurea Baroni. A uberização da relação individual de trabalho na era digital e o direito do trabalho brasileiro. Cadernos de Dereito Actual, Santiago de Compostela, no 7, 2017, p. 257-271. 
SLEE, Tom. Uberização: a nova onda do trabalho precarizado. São Paulo: Editora Elefante, 2017.

UBER NEWSROOM: Fatos e dados sobre a Uber. Publicado em 27 de agosto de 2020. Disponível em: https://www.uber.com/pt-BR/newsroom/fatos-e-dadossobre-uber/. Acesso em 15 de abril de 2020.

Submissão: 30 de outubro de 2020

Aceite: 15 de fevereiro de 2021

Autoria:

Raianne Liberal Coutinhorraianne.lc@hotmail.com

Mestranda do Programa de Pós-Graduação em Direito da Universidade de Brasília (PPGD-UnB). Pesquisadora do Grupo "Trabalho, Constituição e Cidadania".

https://orcid.org/0000-0001-8717-3497

\section{Como citar este documento:}

COUTINHO, Raianne Liberal. Uberização das relações de trabalho: uma abordagem transnacional a partir da interrelação entre Direito Público e Privado. Revista Eletrônica do CEJUR, v. 2, n. 5, $\quad$ set/dez 2020. doi:http://dx.doi.org/10.5380/cejur.v2i5.77625. 